\title{
SUSTAINABLE INDUSTRIAL SYSTEM (SIS)
}

\author{
Odd Myklebust \\ SINTEF, Trondheim, Norway, Email: Odd.Myklebust@sintef.no
}

\begin{abstract}
Sustainability is a topic which is important both for national and international research. Sustainability can both be a competitive factor for manufacturing industry but also reduce the competitiveness with cost driving environmental legislation for a single region e.g. EU only. Approaches for sustainability claim to have both a holistic and international views. They need to manage the product life cycle and keep track of the information flow within of all the lifecycle phases of the product. A special attention is kept on End of Life Management (EOL)
\end{abstract}

Key words: Sustainability, Product Life Cycle, International, Industry, Standardization, End of Life Management

\section{INTRODUCTION TO SUSTAINABLE INDUSTRIAL SYSTEM (SIS)}

The Sustainable Industrial Systems (SIS) approach brings together the different challenges and dimensions of sustainability into a common platform comprising a system oriented approach for industry. As a result, this will lead to improved methodologies, easier and clearer standards and legislations. One important factor that has been almost absent in research projects is the consumer and market relation, which has been called the consumption paradigm.

SIS's overall goal is to obtain a holistic view of product cycles in the manufacturing industry and optimize the life-cycle of industrial systems, products and services. Methodologies and tools to support the manufacturing of products and production must be increasingly life-cycle and service

Please use the following format when citing this chapter:

Myklebust, Odd, 2006, in International Federation for Information Processing (IFIP), Volume 207, Knowledge Enterprise: Intelligent Strategies In Product Design, Manufacturing, and Management, eds. K. Wang, Kovacs G., Wozny M., Fang M., (Boston: Springer), pp. 637-642. 
oriented, in addition to the requirements of intelligence, cost-effectiveness, safety and cleanliness. The objectives are to:

- Combine the environmental dimension of product development and manufacturing and plant operations

- Develop viable and sustainable industrial systems that support customer satisfaction in a sustainable consumption paradigm.

- Develop corporate social responsibility (CSR) principles

- Develop a framework for business organizations to measure progress of commitment and results regarding environmental, economic and social criteria.

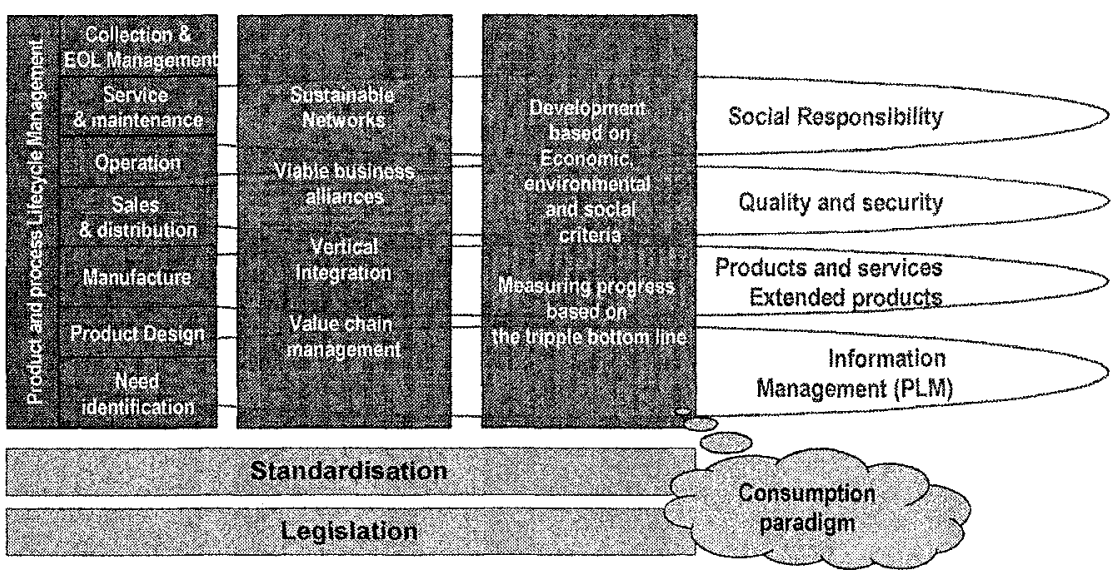

Figure 1. Illustration of The Sustainable Industrial System framework.

The modules in SIS, as they are shown in Figure 1 above, can shortly be described as follows:

- Product and Process Lifecycle Management

- Sustainable Network creation (sustainable extended enterprise)

- Social- economical- ecological combined assessment and performance measurement.

This will lead to a Sustainable Industrial Development Model where:

- Non-renewable resources can be used only at the rate where alternatives are developed or loss of opportunity compensated

- Waste and emissions should not be generated at rates that exceed the ecosystem capacity to assimilate them

- Renewable resources should not be used at rates that exceed the systems ability to replenish itself 


\subsection{Product - service}

Product Service System strategies where products and services are seen as mutually interrelated systems, may contribute to separate economic growth from growth in material and energy throughput, and thereby contribute to the required dematerialization goals. There is a growing understanding among industrialists and policymakers that environmental initiatives need to be seen in relation to each other rather than in isolation.

Technological challenges involve understanding and improving the effectiveness of the material and energy flows. Social challenges are linked to how to redirect society at large, companies and individuals towards a more cyclic- and systems-thinking on production and consumption. The relationships between the different disciplines are vital to understand the action-effect mechanisms and interpret incentives to obtain desired results.

\subsection{Product lifecycle information management (PLM)}

PLM can be described an a strategic business approach that applies a consistent set of business solutions in support of the collaborative creation, management, dissemination, and use of product definition information across the extended enterprise from concept to end of life.

PLM is for the manufacturing industry looking to improve business performance. PLM should consolidate business activities that create, modify and use data to support all phases of a product's life cycle. PLM technology with seamless access to product model structures with data and information on the one hand and distributed knowledge repositories.

Functionality for handling product information of Middle of life (operational phases) and End Of Life (recycling phases) are limited conceived up to now. In a end of life perspective the product model supported by the PLM system also need to "reincarnate" product or material data for reuse of material and/or parts (closing the information cycle).

\section{INDUSTRIAL ECOLOGY CHALLENGES}

\subsection{Improvements within an organization}

Within a company the challenge is to make environmental improvements in accordance with industrial ecology principles along the internal value chain. In product development central aspects are design and material choices that secure good quality, long life for the product, and reuse and 
recycling. In production processes the challenges are to optimize the use of energy and materials. In the final link, the distribution processes, the challenges are to distribute and redistribute the products for use and reuse/end-of-life treatment with a minimum of environmental impact.

\subsection{Value chain management}

Industrial ecology goes beyond conventional environmental work in industry by expanding the system borders of a company. These transactions and actions have environmental impacts, and by organizing them together and looking for synergies, major environmental improvements at a system level can be achieved. The customer relationship between manufacturers gives opportunities for demanding environmental performance to be the preferred supplier. A manufacturer has a lot of suppliers and dealers, and by putting forward environmental demands one single company can create large environmental chain reactions far beyond its own organizational borders. The challenge is to understand how green chain reactions are started and managed.

\subsection{End-of-Life of Product Systems}

The EU project AEOLOS (An End-of-Life of Product Systems) developed an integrated methodology and a toolset that examine the issues relating to the overall sustainability of the End-Of-Life (EOL) treatment of waste products. The AEOLOS methodology enables users to systematically define EOL products and processes to a level of detail that will allow meaningful economic, environmental and societal costs and values of different EOL scenarios. Targeted users include resource recovery and recycling companies, original equipment manufacturers (OEM), and policy makers.

\subsubsection{Background and Project Definition}

The AEOLOS EOL methodology is designed to enable users to define product and process to a level of detail that will allow meaningful economic, environmental and social costs and values of different EOL scenarios to be calculated, analyzed and compared. In so doing, the methodology will assist the user to determine the most sustainable treatment of EOL products [1]. 


\subsubsection{The Step-By-step Methodology for End of Life Management}

The methodology comprises four main steps, preceded by user and facility / product set-up steps [2].

- Step 1 Scenario definition

Select a product and EOL option(s), which together make up an EOL scenario. The definition of the scenarios is unlimited by any constraints, such as local availability of facilities - the refinement of scenarios occurs later in the "loop". The EOL options included in the AEOLOS methodology and software are re-manufacturing, component reclamation, material recycling, incineration with energy recovery, incineration without energy recovery, and landfill. The minimum amount of information required for a product definition is the weight of that product.

- Step 2 Scenario assessment

Select which environmental, social and economic indicators are to be calculated. A description of each indicator will be provided by the system. Once the indicators have been selected, data are entered for the selected indicators. In some cases data is supplied by the software, for instance, the environmental inputs and outputs associated with consumption of energy.

- Step 3 Scenario Analyses

Analyze results (and compare scenarios). The user can choose the method of analysis from a "toolbox" of methods, which range from a simple comparison of indicator results, though to more complex multi-criteria decision analysis techniques.

- Step 4 Scenario Refinement

Checklist of questions to ensure that the preferred scenario is feasible is:

- Check system boundaries and allow adjustment

- Collect more data in order to be able to calculate more indicators

- Seek expert opinion on feasibility of scenarios

- Check local capacity for implementation of a scenario.

\section{CONCLUSION, SUSTAINABILITY IN AN INTERNATIONAL DIMENSION:}

Sustainability within a industrial international society is overall important. This should concern both future international R\&D framework programs and national programs. Unless research within environment and sustainability 
does not obtain a global perspective the main challenges will never be met. Therefore we need to find international activities and agreements that try to include the whole world like the Rio- and Kyoto agreements. The programs can be made a driver to focus on important international topics such as sustainability. This is overall important when we se the growth in the global industrialization and the total growing consume in material and energy.

\subsection{Methods for End Of Life treatment}

In Europe the regulations for recycling products has been developed for quite a while. EU has the e.g. WEEE regulative and the automotive recycling regulative. This is probably just a start of to treat product in middle of life and end of life in the future. This is a typical topic that can be made global. The global waist streams could be made optimal and the methods and regulations for recycling of the products could be standardized.

\subsection{Green logistics}

Industry is global and they work in networks and chains. Products and parts are distributed all over the world. For every mile of transport $\mathrm{CO} 2$ gas is sent out in the air. A more balanced assessment models between transport, cost and environmental factors should be developed. This is important both for logistics in manufacturing and distribution and the return logistics after end of life treatment.

\subsection{Standardization}

At present, national and international standardization and legislation act as guidelines and frameworks for direct regulations and normative value settings. A significant contribution to further development and enhancement of national and international standards and legislations within environment and sustainability is an important activity that must continue.

\section{REFERENCES}

1 Adda, S., Bruce, W 2 Goggin, K., Ray, E. and Lamvik, T., (2001), Goal and Scope, AEOLOS internal deliverable 1.1.

2 Adda, S., Snaddon, K., Goggin, K., Thurley, A., Lamvik, T., Miljeteig, G., Schnatmeyer, M. and Bufardi, A., (2002), The AEOLOS Methodology. AEOLOS internal deliverable 5.2 . 